\title{
Research on Pollution Characteristic of Urban Runoff in Storm Sewer
}

\author{
Chen Weiwei* \\ Yellow River Institute of Hydraulic Research, Key Laboratory of Yellow River Sediment Research, the Ministry of Water Resources, \\ Zhengzhou 450003, China
}

\begin{abstract}
Taking urban roof as the catchment area in Xinxiang City, researching on the hydrology and water quality process of each rainfall event in storm sewer can provide the basis for effectively using urban rainfall and controlling non-point source pollution, and so on. The samples were taken to analyze the contents of SS, COD and TN. The results show that the variation trend of pollutant index SS, COD in runoff is similar and tends to be a steady value. TN decreased with the accumulation of rainfall, but rebounded before the end of rainfall. The standard deviation rate of water quality indicator is SS $>$ COD $>$ TN. The roof flush effect is obvious at the initial stage of runoff, and the initial runoff amount can be defined as the first $1-3 \mathrm{~mm}$ rainfall. The correlation of SS, COD and TN is good in runoff, and measures can be taken to remove them simultaneously in controlling the runoff pollution. The runoff pollutants flow into the receiving water directly through urban drainage pipe network, and have a great effect on its water quality, especially the changes of SS and COD are the most obvious.
\end{abstract}

\section{Introduction}

The Urban roof is an important part of urban impervious surface type. The accumulated pollutants form roof runoff under the rain erosion, which becomes a main source of urban water environment pollution ${ }^{[1]}$. Since the 1970 s, foreign countries have successively carried out research on the process and characteristics of urban rainfall runoff pollution and its impact on the water quality of receiving water, the effect of runoff scouring in the early stage of different types of underlying surfaces ${ }^{[2-4]}$ and the severity of urban rainfall runoff pollution. The research on urban non-point source pollution has been carried out in China from the end of 1980s. Great progress has been made in rainfall runoff change process under different types of underlying surface, rainwater runoff pollution characteristics and influencing factors and initial scouring effect ${ }^{[5-9]}$.

At present, the drainage pipe network in Xinxiang City is $1519 \mathrm{~km}$ long, including $730 \mathrm{~km}$ of sewage pipe, $491 \mathrm{~km}$ of rainwater pipe and $298 \mathrm{~km}$ of rainwater and sewage combined pipe. The separate system pipe network is the main channel to discharge rainfall runoff. In this study, the rainfall runoff process of the separate system rainwater pipe network in Xinxiang City was tested, and the water quality change characteristics of the roof runoff after flowing into the rainwater pipe network and the impact on the water quality of the receiving water body were studied, providing theoretical support for the control of urban runoff pollutants and the calculation of non-point source pollution load.

\section{Research plan}

\subsection{Test monitoring}

The test site is located on the top of an office building in Xinxiang City, and the underlying surface is asphalt SBS waterproof material. The sampling area is rectangular, $18.05 \mathrm{~m}$ in length and $7.50 \mathrm{~m}$ in width. One rainwater pipe is arranged. In case of natural rainfall, $75 \mathrm{~L}$ polyethylene bucket is used to collect rainwater runoff. The rainfall hydrograph is obtained synchronously by the automatic weather station, and the rainfall intensity at different times is calculated according to the accumulated rainfall data. Then, the instantaneous runoff calculated by the single sampling time and container volume is taken as the median runoff at the beginning and end of sampling, and the rainfall and runoff intensity are used to describe the hydrological and hydraulic process of each rainfall.

The monitoring time is August 4, August 10, August 13, 2017 and November 8, 2019. The rainfall lasts $195 \mathrm{~min}, 225 \mathrm{~min}, 325 \mathrm{~min}$ and $450 \mathrm{~min}$. The rainfall is $4.01 \mathrm{~mm}, 51.79 \mathrm{~mm}, 68.28 \mathrm{~mm}$ and $5.25 \mathrm{~mm}$. The average rainfall intensity is $0.021 \mathrm{~mm} \cdot \mathrm{min}^{-1} 、 0.23 \mathrm{~mm} \cdot \mathrm{min}^{-1}$ 、 $0.21 \mathrm{~mm} \cdot \mathrm{min}^{-1}$ and $0.012 \mathrm{~mm} \cdot \mathrm{min}^{-1}$.

The $500 \mathrm{ml}$ polyethylene bottle was used to collect the water sample of runoff analyzed according to the national environmental monitoring standard method after collection. The water quality indexes include SS, COD and TN. SS was analyzed by the solid suspension determination, COD was analyzed by the chemical oxygen demand speed measuring devices, and TN was

\footnotetext{
* Corresponding author: 398502376@qq.com
} 
analyzed by the Alkaline Potassium Persulfate Digestion-UV Spectrophotometric Method. Generally, the sampling frequency is 1 sample every 5 minutes within 30 minutes since the runoff generation; 1 sample every 15 minutes within 30-60 minutes after the runoff producing; and 1 sample every 30 minutes thereafter.

\subsection{Analysis method}

\subsubsection{Average field concentration}

The ratio of the total amount of pollutants in the rainfall to the total amount of runoff, that is, the weighted average concentration of pollutants in the runoff process, is used as a method to evaluate runoff quality ${ }^{[8]}$. Calculated by formula (1):

$$
E M C=\frac{M}{V}=\frac{\int_{0}^{t_{V}} C_{t} Q_{t} d t}{\int_{0}^{t_{V}} Q_{t} d t}=\frac{\sum C_{t} Q_{t} \Delta t}{\sum Q_{t} \Delta t}
$$

Where, $E M C$ is the average concentration of runoff pollution, $\mathrm{mg} \cdot \mathrm{L}^{-1} ; M$ is the total amount of runoff pollutants, $\mathrm{g} ; V$ is the total amount of runoff, $\mathrm{m}^{3} ; t$ is the time, min; $C_{\mathrm{t}}$ is the concentration of pollutants in $t$ moment, $\mathrm{mg} \cdot \mathrm{L}^{-1} ; Q_{\mathrm{t}}$ is the runoff flow in $t$ moment, $\mathrm{m}^{3} \cdot \min ^{-1} ; \Delta t$ is the sampling interval, $\min$.

\subsubsection{Standard deviation rate}

The standard deviation rate is used to analyze the change range of the pollutants ${ }^{[6]}$ to eliminate the effect of the large difference in pollutant concentrations. Calculated by formula (2):

$$
V=\sqrt{\frac{1}{n} \sum_{i=1}^{n}\left(X_{i}-\bar{X}\right)^{2}} / \bar{X} \quad(i=1,2, \cdots n)
$$

Where, $X_{\mathrm{i}}$ is the concentration of pollutants, $\mathrm{mg} \cdot \mathrm{L}^{-1}$; $\bar{X}$ is the mean value of concentration, $\mathrm{mg} \cdot \mathrm{L}^{-1} ; n$ is the number of samples, and $V$ is the standard deviation rate.

\subsubsection{Pollutant loading rate}

Analyze the relationship between pollutant loading rate and rainfall [7], and calculate from equation (3):

$$
l=Y_{h} / Y
$$

Where, $Y_{h}$ is the pollution loading when the rain is $h$, $\mathrm{g} ; Y$ is the total pollution loading of each rainfall, $\mathrm{g}$; $h$ is the cumulative rainfall, $\mathrm{mm} ; l$ is the pollutant loading rate, $\%$.

\section{Results and discussion}

\subsection{Analysis of Water Quality Characteristics of Rainfall Runoff in Rainwater Pipe Network}

According to the test results, the variation range of each index, the average concentration of the sessions and the standard deviation rate are shown in Table 1. which show that the EMC value range of SS is $11.42 \sim 113.49$ $\mathrm{mg} \cdot \mathrm{L}^{-1}, \mathrm{COD}$ is between $21.89 \sim 865.31 \mathrm{mg} \cdot \mathrm{L}^{-1}$, and TN is between $12.69 \sim 21.53 \mathrm{mg} \cdot \mathrm{L}^{-1}$. For the four rainfalls, the peak time of the concentration of the pollutants and the peak time of the rainfall intensity are basically the same, and they generally appear within 10-15 minutes after the runoff, and then gradually decrease in concentration as the rainfall process continues.

Among the pollutants, SS and COD changed the most, and the concentration decreased rapidly in the initial stage of runoff, then gradually slowly decreased and tended to a stable value. TN has a large range of change, and gradually decreases with the accumulation of rainfall, but rebounds before the end of rainfall. From the standard deviation of each index, it shows the trend of $\mathrm{SS}>\mathrm{COD}>\mathrm{TN}$, which is basically consistent with the directivity of each concentration change process, and the standard deviation of SS and COD is large, which is consistent with the fact that the concentration changes greatly in the test process.

The variation characteristics of each index concentration in runoff are closely related to the law of pollutant cumulative discharge. Generally, the pollutants in Xinxiang City are mainly accumulated from autumn to spring, and the frequent rainfall in summer is mainly discharged. Pollutants mainly come from the leaching of the atmosphere by rainfall, the erosion of roof sediments by rainwater runoff and the roofing materials themselves, mainly including COD, SS, TN, TP, inorganic salt and other pollutants. Affected by the above factors, the change of water quality index is as described above. It can be seen that the characteristics of rainfall runoff quality of rainwater pipe network are related to urban location, underlying surface type, rainfall, rainfall intensity, rainfall interval, management level and other factors, and the indicators of rainfall runoff quality fluctuate greatly in different times.

Table 1 Water quality index in runoff

\begin{tabular}{ccccc}
\hline Rate & Project & $\mathrm{SS} / \mathrm{mg} \cdot \mathrm{L}^{-1}$ & $\mathrm{COD} / \mathrm{mg} \cdot \mathrm{L}^{-1}$ & $\mathrm{TN} / \mathrm{mg} \cdot \mathrm{L}^{-1}$ \\
\hline & Rang & $50 \sim 511$ & $172.5 \sim 2591.4$ & $11.98 \sim 38.41$ \\
$8-4$ & Standard deviation rate & 0.82 & 0.68 & 0.34 \\
& EMC & 113.49 & 674.29 & 21.53 \\
\hline \multirow{2}{*}{ 8-10 } & Standard deviation rate & 0.57 & 0.45 & 0.16 \\
& EMC & 11.42 & 27.74 & 12.69 \\
\hline \multirow{4}{*}{ 8-13 } & Standard deviation rate & 2.22 & 0.76 & 0.43 \\
& EMC & 26.22 & 21.89 & 13.97 \\
\hline \multirow{4}{*}{ 11-8 } & Standard deviation rate & 0.75 & 0.41 & 0.24 \\
& EMC & 101.57 & 865.31 & 14.51 \\
\hline
\end{tabular}

\subsection{Analysis of the initial erosion effect of rainwater pipe network}

In this study, SS, COD and TN are used as pollutant indexes to analyze the initial erosion effect of rainwater 
pipe network. According to the change curve of water quality index, the SS content, COD content and TN content in the initial runoff (first $15-20 \mathrm{~min}$ ) are about $18-591 \mathrm{mg} \cdot \mathrm{L}^{-1}, 20.3-2591.4 \mathrm{mg} \cdot \mathrm{L}^{-1}$ and $14.2-40.72 \mathrm{mg} \cdot \mathrm{L}^{-1}$, respectively; in the later period, the SS content is about $9-127 \mathrm{mg} \cdot \mathrm{L}^{-1}$, COD content is about $7.6-1011.5 \mathrm{mg} \cdot \mathrm{L}^{-1}$, TN content is about $9.4-26.43 \mathrm{mg} \cdot \mathrm{L}^{-1}$. According to the relationship between pollution index content and runoff during the period, it can be seen that the average concentration of each index not only exceeds the requirements of class $\mathrm{V}$ water in the Environmental Quality Standard for Surface Water (GB3838-2002), but also exceeds the class I B standard for class III and IV $\mathrm{V}$ water discharged into the surface water in the Discharge Standard for Pollutants from Urban Sewage Treatment Plants (GB18918-2002). The concentrations of SS, COD and TN are higher in the early stage of runoff, and decrease gradually with the continuous rainfall process, showing a certain initial erosion effect.

The variation process of SS, COD and TN loading rates in runoff with rainfall is shown in Figure $1 \sim 3$. In the early stage of rainfall, the increase rate of pollutant loading rate is faster, and when the rainfall reaches a certain value, the increase rate of pollutant loading rate decreases. In general, when the rainfall is $1 \sim 3 \mathrm{~mm}$, the pollutant loading rate can reach more than $60 \%$. When the rainfall is more than $3 \mathrm{~mm}$, the increase rate of pollutant load decreases. It can be seen that the initial runoff of the roof can be determined as the first $1-3 \mathrm{~mm}$ rainfall.

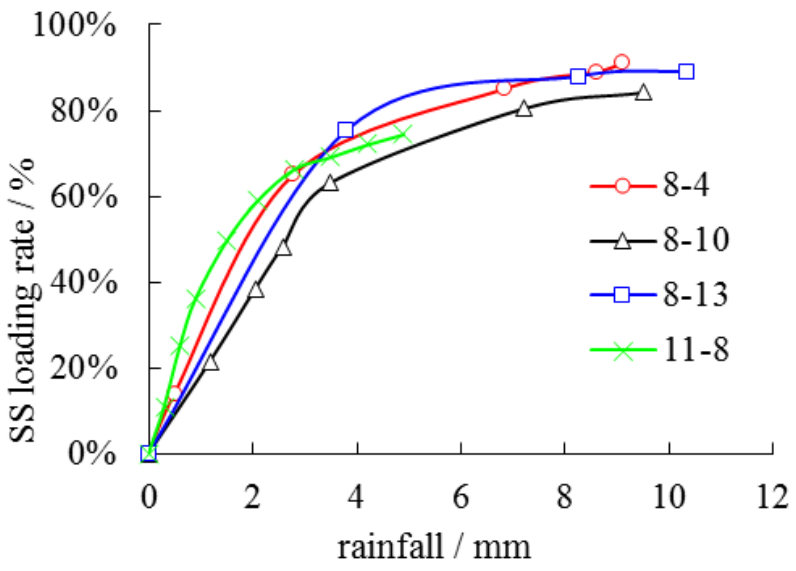

Fig. 1. Variation of SS loading rate with rainfall in runoff

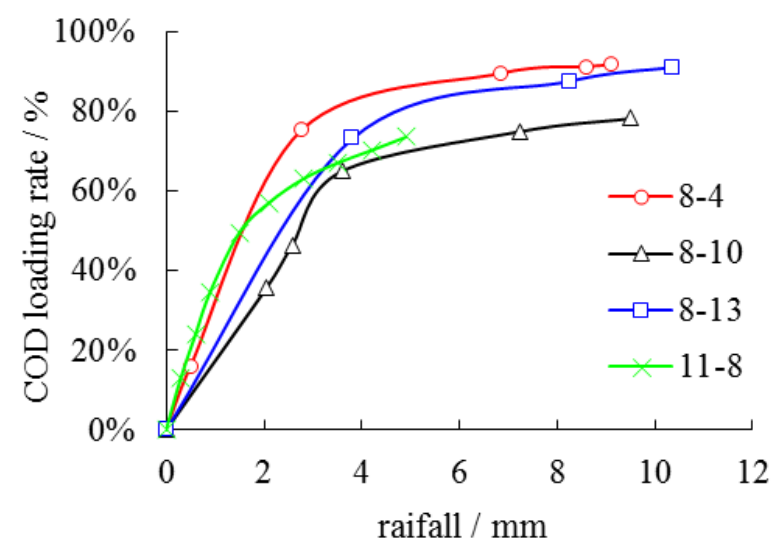

Fig. 2. Variation of COD loading rate with rainfall in runoff

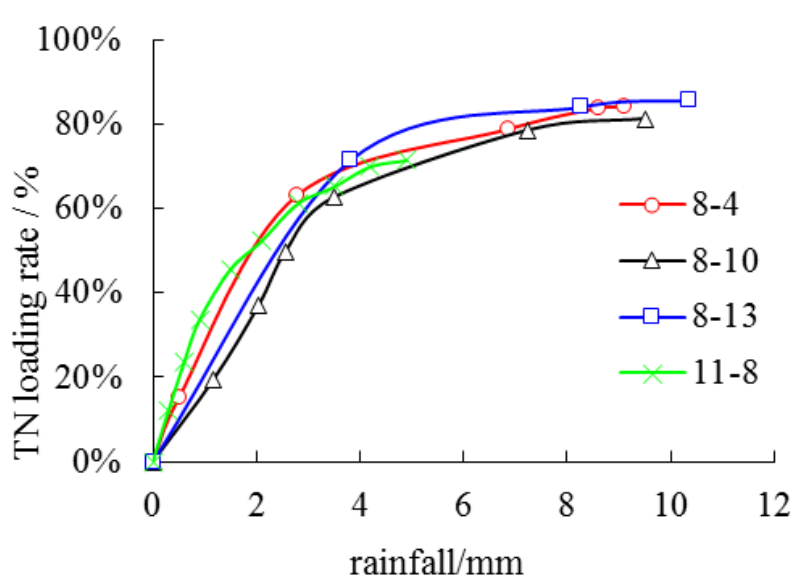

Fig. 3. Variation of TN loading rate with rainfall in runoff

\subsection{Correlation analysis of pollutants}

In this study, SS, COD and TN are used to represent particulate matter, organic matter and inorganic matter, respectively, to analyze the correlation between pollutants in the pipe network runoff, as shown in Figure 4. The results show that SS has a strong correlation with COD and TN (significant level is above 0.1), and the correlation coefficients are 0.92 and 0.89 respectively. The main reason is that the atmosphere in this area is mainly characterized by dust fall, the interval time of rainfall is long, and particles such as micro dust can be greatly supplemented. Under the condition of rainfall, the pollutants carried by them are dissolved into the runoff, resulting in the increase of the concentration of COD and TN. In addition, it also shows that the synergy between SS, COD and TN is good, and a unified method can be used to remove the pollution at the same time when the runoff pollution control measures are formulated. For example, pollution load in roof runoff can be effectively controlled by environmental cleaning, rainwater runoff interception, sedimentation or filtration.

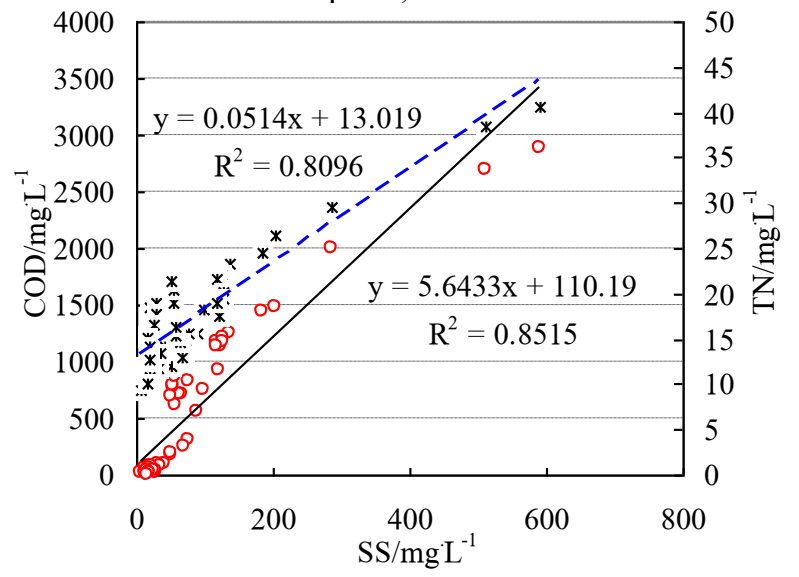

Fig. 4. The correlation between $\mathrm{COD}, \mathrm{TN}$ and $\mathrm{SS}$ in rainwater pipe network 


\subsection{The influence of the pollutants from the rainfall runoff of the pipe network on the water quality of the receiving water body}

During the experiment, the roof rainfall runoff is directly transmitted to the receiving water body ( Weihe River, the tributary of Haihe River Basin ) through the urban diversion system pipe network without any treatment, which has an impact on the water quality. It can be seen from the analysis of the impact of runoff pollutants on the water quality of the section of Weihe East Main Bridge that the section flow begins to increase within 1520 minutes after the start of rainfall, which indicates that the pipe network runoff begins to enter the receiving water body. Within 3.5-4 hours after the start of runoff, the concentration of pollutants appears a peak, the concentration of SS increases from $34 \mathrm{mg} \cdot \mathrm{L}^{-1}$ before the rain to $126 \mathrm{mg} \cdot \mathrm{L}^{-1}$, the concentration of COD from 75 $\mathrm{mg} \cdot \mathrm{L}^{-1}$ to $247 \mathrm{mg} \cdot \mathrm{L}^{-1}$, and the TN from $2.7 \mathrm{mg} \cdot \mathrm{L}^{-1}$ to $23.1 \mathrm{mg} \cdot \mathrm{L}^{-1}$. SS and COD increased the most, and the water quality in 1.5-2 days after the end of rainfall basically recovered to the condition before rain. According to the change curve of water quality index, there is a certain difference in the time when the peak concentration of water body monitoring section occurs. On August 4 and August 10, the peak value of SS and COD appears first, and the peak value of $\mathrm{TN}$ appears after the interval of about 1.4-1.8h; on August 13 and November 8 , the peak value of water body monitoring section appears in double peak type, the first peak value appears in 1.7-2.5h after the runoff, the second peak value appears in $4.5-5 \mathrm{~h}$ after the runoff with the largest increase in SS and COD. It can be seen that the nonpoint source pollution of urban roof is a long-term and dynamic process, which has the characteristics of complexity and randomness. The problems related to the pollution load caused by the rainfall runoff erosion of urban roof, the impact on the receiving water body, pollution control measures and so on need to be further studied by means of prototype test, theoretical analysis, model construction and calculation.

\section{Conclusions}

(1) The variation trend of SS and COD in the runoff quality index of roof is basically the same, and their concentration gradually decreases and tends to a stable value with the continuous rainfall. TN decreased with the rainfall accumulation, but rebounded before the end of rainfall. The trend of standard deviation of indicators is $\mathrm{SS}>\operatorname{cod}>\mathrm{TN}$, which is consistent with the directivity of their concentration changes.

(2) At the initial stage of runoff, the concentration of pollutants is high, and then gradually reduces, showing a certain initial erosion effect. The initial runoff of roof is the first $1 \sim 3 \mathrm{~mm}$ rainfall.

(3) The correlation of SS, COD and TN in runoff is good, which shows that measures can be taken to remove particles, organic matter and inorganic matter at the same time when controlling runoff pollution.
(4) Runoff pollutants directly flow into the receiving water body through the urban drainage pipe network, which has a great impact on the water quality, especially the changes of SS and COD.

\section{Acknowledgement}

This research was supported by a grant from: The National Key R\&D Program of China (2017YFC0504503) and The Technology demonstration project of the Ministry of Water Resources (SF-201802). Deeply grateful!

\section{References}

1. ZHANG Wei. Environmental Behavior of Toxic Pollutants in Urban Runoff[M]. Beijing: Scientific and Technical Documentation Press, 2014.

2. LI Liqing, YIN Chengqing. Transport and Sources of Runoff Pollution from Urban Area with Combined Sewer System[J].Environmental Science, 2009, 30 (2): 368-375.

3. CHEN Weiwei, ZHAN Xiaolai, CAO Huiti, etc. Research Advance of Urban Rainfall-Runoff Nonpoint Source Pollution[J]. Water Saving Irrigation, 2011, (12): 50-52.

4. PAN Anjun, ZHANG Shuhan, CHEN Jiangang, etc. Technology Research and Application of Urban Rainwater Comprehensive Utilization [M]. Beijing: China Waterpower Press, 2010.

5. QI Saijun, WANG Yongtao. Analysis of Flush Rule in Initial Stage of Rainwater Runoff in Typical Gathering Ground of Suzhou [J]. Environmental Science and Technology, 2011, 24(s1): 41-43.

6. DONG Xin, DU Pengfei, LI Zhiyi, etc. Hydrology and Pollution Characteristics of Urban Runoff: Beijing as a Sample[J]. Environmental Science, 2008, 29(3): 607-612.

7. CHEN Weiwei, ZHANG Huimin, HUANG Fugui, etc. Research on Characteristics of Hydrology and Water Quality on Rainwater Runoff of Urban Roof $[\mathrm{J}]$. Journal of Water Resources and Water Engineering, 2011, 22(3): 86-88.

8. REN Nanqi, FENG Yujie, CHEN Wei, etc. Pollutants transformation law and resource theory and technology of urban water system[M]. Beijing: Beijing Science Press, 2012.

9. Geiger W. Flushing effects in combined sewer systems // Proc. $4^{\text {th }}$ Int. Conf. on Urban Storm Drainage [C]. Lausanne, Switzerland, 1987, 40-46. 